\title{
LA REPRESIÓN DE LA VIS EN ÉPOCA REPUBLICANA
}

\author{
VICTORIANO SAIZ LÓPEZ \\ Titular de Universidad de Derecho Romano
}

El presente trabajo, dedicado a la represión de la vis en época republicana, plantea la cuestión desde una perspectiva que no se limita al derecho penal público: la posible configuración de un determinado hecho violento como crimen vis $\mathrm{y}$, al mismo tiempo, como lesión de intereses particulares y la concurrencia de medios de derecho privado y público nos llevan a una consideración conjunta de varias instituciones que tienen por objeto la sanción de la violencia ilícita.

Se trata, en la defensa interdictal, los mecanismos edictales y la legislación penal, de precisar el espacio en que se mueven las distintas acepciones que el término adquiere en las fuentes e, igualmente, de explicar las distinciones que dentro del mismo se establecen.

Esto supuesto, la explicación de la distinción vis privata et publica, que ha dado lugar a una gran variedad de hipótesis en la doctrina, según el punto de vista adoptado, resulta de especial importancia para entender las dos vertientes en que actúa la vis del derecho criminal romano.

Considerando el criterio que preside la Compilación Justinianea, vemos, por un lado, que el Digesto atiende al carácter de las penas, más graves en la vis pública que en la vis privata (interdicción de agua y fuego y confiscación de la tercera parte de los bienes, respectivamente), mientras que de las Instituciones se deduce que la vis publica se caracteriza por el uso de armas y que la vis privata es fuerza sine armis. Tales criterios de distinción no pueden corresponder a los originarios.

A partir de aquí, la doctrina ha elaborado diferentes esquemas sobre el alcance jurídico de la dualidad en cada una de las fases de evolución del Drecho Romano.

Desde Cuiacio se define la vis pública "quae contraria est rei, iurive publico", la vis privata «quae est contraria rei, iurive privato»; en otro contexto, se distinguen las dos formas de vis según que el autor del ilícito sea un magistrado o un ciudadano en particular.

Esta y otras opiniones modernas pueden y deben interpretarse desde una visión plural, en la que tengan cabida varias posibilidades, en función del momento histórico, del jurista o del campo jurídico específico en que nos movamos.

En efecto, los tratados de derecho penal de Ferrini Mommsen, con una perspectiva procesal, presentan la vis publica como infracción del ordo iudiciorum publicorum, la vis privata, vulneración del ordo iudiciorum privatorum; esto justificaría la identificación de las leges Iuliae de vi con las leges Iuliae iudiciorum. 
Otros, entre los que se incluyen los estudios de Costa sobre el crimen vis, explican que el criterio distintivo derivaría del sector del ordenamiento jurídico (público o privado) que la violencia ilícita quebranta.

Por su parte, Luzzatto, en sus investigaciones sobre procedimiento civil romano, no defiende un preciso criterio sistemático, pues cadailícito, con su correspondiente pena, vendría clasificado en la lex Iulia de vi publica o de vi privata, en cada momento, según su mayor o menor gravedad con respecto a la estabilidad social.

Y recientemente, L. Vacca, a propósito de la rapina en Derecho Romano, ha puesto de manifiesto que la legislación sobre el crimen vis, en la República, no sólo habría sancionado casos de violencia política sino también otros de violencia contra los particulares que, por su trascendencia, significan una amenaza para la paz social y el orden público.

\section{1.- Vis en el procedimiento interdictal ${ }^{1}$}

En materia de procedimiento interdictal, el término vis resulta repetidamente utilizado en las fuentes. Expresiones como vim fieri veto o ne vis fiat vienen aplicadas en la terminología edictal relativa a los interdicta prohibitoria. En este sentido, la locución vim fieri veto aparece en el texto del interdicto uti possidetis y sirve para delimitar la extensión de la prohibitio. Por otro lado, bajo la rúbrica edictal unde $v i$, el pretor sanciona los supuestos de expulsión violenta de inmuebles mediante los interdictos de vi cottidiana y de vi armata. Las cláusulas referidas al de vi y al de vi armata se caracterizan por el empleo de la fórmula vi deicere con la que se expresa la forma de violencia que tienen por objeto.

Supuestas estas ideas y tras un primer análisis de las fuentes que se ocupan del tema interdictal, puede afirmarse que el término vis no tiene una sola acepción; por el contrario, su significado jurídico varía según el contexto y en relación al instituto al que, cada momento, resulta aplicable. Sinos referimos a los interdictos prohibitorios, los juristas romanos entienden la vis en un sentido amplio: Pomponio, en efecto, entiende que vim facit quien, con cualquier comportamiento positivo en relación con las cosas (quidomninofaciendo), impida el libre ejercicio de las facultades posesorias²; con lo cual el concepto de violencia comprende diversas actividades que superan un sentido estricto. Si nos referimos al interdicto de vi cottidiana, y nos fijamos en los términos que se expresa Ulp. 69 ad ed.:

Hoc interdictum non ad omnem vimpertinet, verum ad eos, qui de possessione deiciuntur ${ }^{3}$,

'Berger, V. Interdictum en PWRE

${ }^{2}$ D. 43, 16, 11 (Pomp. 6 ex Plautio)

${ }^{3}$ D. $43,16,1$ 
admitiéndolos como sustancialmente válidos para el derecho clásico, podremos afirmar que este interdicto no sanciona cualquier clase de violencia sino aquélla mediante la cual se priva a alguien de la posesión de un determinado bien. En este sentido, Balzarini ${ }^{4}$ analiza los distintos fragmentos en los que se trata de la posible aplicación de los interdictos de vi y de vi armata y concreta los supuestos del siguiente modo:

a.- deiectio efectuada por un solo individuo $0^{5}$

b.- sospecha de la presencia de un individuo cum $\mathrm{armis}^{6}$,

c.- metus provocado por un individuo armado ${ }^{7}$,

d.- metus provocado por una turba ${ }^{8}$,

e.- metus, más o menos justificado, al observar hombres armados ${ }^{9}$,

f.- sospecha de la presencia de hombres $\operatorname{armados}^{10}$,

g.- los casos precedentes, sin distinción ${ }^{11}$ : donde se considera suficiente en la configuración de la deiectio la huída del poseedor por el miedo a ser objeto de violencia, siempre que el fundo sea ocupado por el adversario, con lo que se exigiría una correlación entre el hecho material y el metus.

Supuestas estas consideraciones sobre la violencia como presupuesto de los interdictos posesorios, cuyo alcance varía según se trate del uti possidetis, de vi, o de vi armata, y su directa conexión con el miedo (metus), se debe ahora tener presente el tema del procedimiento y de la correspondiente sanción de la vis en época republicana ${ }^{12}$.

Si se admite que el sistema interdictal, en origen, constituye una adaptación del imperium del magistrado al procedimiento civil, en ciertos supuestos en que no llega la acción y en los que la seguridad pública exige la superación de toda vía de hecho, también se debe comprender cómo la orden del magistrado, basada en la demanda del interesado, aparece íntimamente enlazada con la posible remisión del caso a un juez, árbitro o tribunal de recuperadores, quienes actúan sobre la base de una acción concedida en virtud de la pretendida violación del interdicto ${ }^{13}$.

En efecto, el interdicto significa para las partes la obligación de respetar la paz pública cuyo incumplimiento dará lugar a la ejecución de un arbitrium o a una sentencia pecuniaria. No debe olvidarse que, al menos por lo que se refiere al derecho clásico, en materia de interdictos prohibitorios, se procede mediante una apuesta

${ }^{4}$ Balzarini, Ricerche in tema di danno violento e reapina nel diritto romano, Padova 1969, p. 134

${ }^{5}$ D. $41,3,4,22$

${ }^{6}$ D. $4,2,9$ pr.

${ }^{7}$ Cic. pro Caec. 47

${ }^{8} \mathrm{D} .43,16,1,29$

${ }^{9}$ Cic. pro Caec. $45-47 ; 49 ;$ D. 41, 3, 33, 2

${ }^{10}$ D. $43,16,3,7$

"P. S. 6, 4

${ }^{12}$ Humbert (Lecrivain), V. Interdictum en D. S.

${ }^{13}$ Cic. pro Tullio 29; G. 4, 141 
solemne (per sponsionem); en los demás casos, se puede optar por una formula arbitraria $^{14}$, como ocurre en las acciones reales del procedimiento formu-lario. En el primer supuesto, la sponsio tiene carácter preiudicialis et poenali ${ }^{15}$; pre-judicial porque significa un compromiso de las partes de plantear el proceso y acatar la decisión judicial sobre el problema jurídico de fondo; penal porque entraña una pérdida añadida para el condenado (periculum). Del litigio se encargarían los recuperatores o el iudex unus ${ }^{16}$. Por lo que se refiere a la fórmula arbitraria: cuando ésta se admite en el sistema formulario, en materia de reivindicatoria, acciones reales, acciones ad exhibendum, finium regundorum, etc., el pretor, en el ámbito de los interdictos restitutorios y exhibitorios, otorga la facultad de escoger esta vía del procedimiento, lá cual admite distintos modos de solución: o bien la absolución, si el demandado ejecuta el arbitrium; o, en caso contrario, mediante la autorización al vencedor de recurrir al magistrado para hacer ejecutar el iussus del arbiter por la fuerza pública ${ }^{17} ; o$, incluso, la de contentarse con una condena pecuniaria de indemnización quanti ea res erit.

En definitiva, si todo esto se considera válido, puede admitirse que la sanción de los actos de violencia ilícita abarca un amplio campo de casuismo edictal en el cual se produce una interesante concurrencia entre la decisión de imperio del magistrado y el correspondiente proceso judicial; el sistema interdictal se inserta, de este modo, en el ordo iudiciorum privatorum y constituye un eficaz complemento en la defensa de los intereses de los particulares. Y ello con independencia de aquellos interdictos que defienden el interés público, en sentido estricto, como los que garantizan el uso común de los bienes públicos.

A propósito de la aplicación del procedimiento interdictal, durante el período republicano, resulta de especial importancia la fijación cronológica de sus fases de evolución, a tenor de los datos de las fuentes.

De este modo, puede considerarse que los interdictos de carácter prohibitorio son los más antiguos: probablemente existen en la época de la ley Cincia de donis etmuneribus del 204 a. de C. ${ }^{18}$. Ahora bien, la mayor parte de los interdicta prohibitoria se dirigen a la protección del específico orden público ${ }^{19}$, como el ne quid in loco sacro, el de sepulcro aedificando,... y, sobre la prohibición de usar la vía pública, un interdicto que utiliza la fórmula vim fieri veto ${ }^{20}$, la cual es utilizada tanto en el campo privado como en el terreno de la administración de los intereses superiores de la comunidad. Esto nos permite rechazar cualquier planteamiento que pretenda

${ }^{14} \mathrm{G} .4,141,163$. La facultad de pedir un árbitro ya viene recogida en Cicerón, pro Tullio 7

${ }^{15} \mathrm{G} .4,141,162$

${ }^{16}$ Cic. pro Caec. 8

${ }^{17}$ D. $6,1,68$

${ }^{18}$ Frag. Vat. 293, 311. Los interdictos uti possidetis y utrubi se aplicarían en el contexto de esta ley. La fecha de la ley es fijada por Cicerón cuando la considera del consulado de Tuditanus y Cethegus. Cic. de senect. 4, 10 (Cuq, V. Lex Cincia en D. S.).

${ }^{19}$ D. $43,6-15$

${ }^{20}$ Quominus illi via publica itinereve publico ire agere liceat, vim fieri veto. D. 43, 8, 2, 45 
justificar la represión de la violencia ilícita exclusivamente en el derecho privado o en el derecho público: desde el primer momento, la idea de simultaneidad nos muestra sus posibilidades de actuación en distintas parcelas del ordenamiento.

En cuanto a los llamados interdictos recuperandae possessionis, el unde vi, a favor de quien por violencia es privado de la posesión de un inmueble, ya viene mencionado en la ley agraria del 111 a. C. ${ }^{21}$. Según el Digesto, la fórmula sería:

Unde tu, Ni Ni, aut familia aut procurator tuus Am Am aut familiam aut procuratorem eius in hoc anno vi deiecisti, qua de re agitur, cum As As possideret, quos nec vi nec clam nec precario a te possideret, eo restituas $^{22}$;

hay una fómula probablemente más reciente en Cicerón:

Unde dolo malo tuo, M. Tuli, M. Claudius aut familia aut procurator eius vi detrusus est... ${ }^{23}$

En rigor, presupuesto del interdicto sería una vis puramente material, pero de la que no se puede excluir el dolo malo o las maniobras fraudulentas: la expresión $v i$ deiecisti no ha de impedir una interpretación jurisprudencial que amplíe el simple juego de una vis material y estricta.

Cuando la expulsión ha tenido lugar mediante la fuerza armada, el pretor concede un interdicto cuya fórmula vendría concebida en los siguientes términos:

Unde tu, Ni Ni, aut familia aut procurator tuus Am Am aut familiam aut procuratorem eius vi hominibus coactis armatisve deiecisti, qua de re agitur, eo restituas ${ }^{24}$.

Características que de la fórmula se derivan son en perpetuidad ${ }^{25}$ y la ausencia de la excepción vitiosae possessionis, quos nec vi nec clam nec precario a te possideret: por ello la víctima de la violencia puede pedir la restitución frente a cualquiera aunque su posesión sea violenta, clandestina o en precario; la gravedad del acto armado de despojo no quedaría justificado en ningún caso, ni siquiera ante un supuesto de posesión viciada en origen.

\section{VIS Y METUS EN LA FORMULA OCTAVIANA (ACTIO METUS)}

En el momento de designar los comportamientos que quedan sujetos a los remedios pretorios incluídos bajo la rúbrica edictal quos metus causa gestum erit ${ }^{26}$,

${ }^{21}$ Corp. inscr. lat. I, $\mathrm{n}^{\mathrm{o}} 200,18$

${ }^{22}$ D. $43,16,5$

${ }^{23}$ Cic. pro Tullio 29

${ }^{24}$ Cic. pro Caec. 21, 22; ad fam. 15, 16; G. 4, 155. Nicosia, Studi sulla deiectio I, Milano 1965, p. 88 ss.

${ }^{25}$ Cic. Epist. 15,16

${ }^{26}$ D. 4,2 ; C. $2,19,(20)$ 
las fuentes utilizan frecuentemente y en sentido complementario los término vis y metus.

Partiendo de D. 4,2, 1 y 3 pr., podemos considerar que con el vocablo vis se designa toda coacción contraria a la voluntad negocial, mientras que con metus se está haciendo referencia a la turbación de la inteligencia por causa de un peligro inminente o futuro. Sin embargo, el comentario de Ulpiano refiere cómo, con posterioridad, fue suprimida la mención de la vis:

Sed postea detracta est vis mentio ideo, quia quodcumque vi atroci fit, id metu quoque fieri videtur ${ }^{27}$.

En efecto, aquí puede entenderse que en la mayor parte de los casos la violencia física (corporal) se transforma en metus, es decir, en violencia moral ${ }^{28}$ : esto resulta válido cuando nos movemos en el terreno de la voluntad negocial viciada, aunque no se pueda decir lo mismo en general, pues desde esta perspectiva la vis mantiene su autonomía:

Vis es maior (is) rei impetus, qui repelli non potest ${ }^{29}$.

En otras palabras, bajo el título 2 del libro cuarto del Digesto, se incluyen dos instituciones jurídicas: la restitutio in integrum ob metum, en virtud de la cual el magistrado declara no reconocer los efectos de un acto jurídico viciado, y la actio quos metus causa frente a quien haya obtenido una ventaja patrimonial sirviéndose del miedo o de la intimidación.

Esto supuesto, se trata ahora de determinar cuál es el contenido jurídico originario de la llamada fórmula Octaviana y cuáles son las posibles razones que justifican la desaparición de la vis en beneficio de la sola mención del metus. A propósito del carácter originario de la formula Octaviana, contamos con la información que nos transmiten los textos de Cicerón, en los que tiene lugar el uso repetido de la conjunción entre los dos términos vis y metus. Así, en in Verrem 2, 3, 65, 152, relata Cicerón cómo Apronio, hombre vinculado a Verres, es llevado ante el tribunal del propretor de Sicilia L. Metelo ${ }^{30}$, a iniciativa del senador C. Galo, en virtud de la fórmula Octaviana, prevista en el edicto provincial de Metelo de ese año, y ya incluída en su edicto del pretor del año precedente en Roma ${ }^{31}$. Los términos en que se expresa Cicerón son inequívocos:

Quos per vim aut metum abstulisset.

Por otro lado, en ad Quintum fratrem 1, 1, 7, 21, cuenta Cicerón que C. Octavio, en el ejercicio de su jurisdicción, obligó a los Sullani homines a

quae per vim aut metum abstulerant reddere.

${ }^{27}$ D. 4, 2,1 (Ulpiano Coment. al Edicto, L. 12). Pasaje que ha dado lugar a un interesante debate doctrinal que podemos concretar en las obras de Maschi, Il diritto romano nella prospettiva storica della giurisprudenza classica, Milano 1957, y de Cervanca, Per la storia dell' Editto quod metus causa (a proposito di D. 4, 2, 1 y 3) SDHI 31, 1965.

${ }^{28}$ Balzarini, Ricerche... cit., p. 139

${ }^{29}$ D. $4,2,2$ y P. S. $1,7,7$

${ }^{30}$ Sucesor de Verres en el 70 a. C.

${ }^{31}$ L. Metelo, pretor en Roma el año 71 a. C. Münzer, V. Caecilius en PWRE 
Partiendo de las expresiones utilizadas, se viene admitiendo que el mecanismo procesal contenido en la originaria redacción de la fórmula Octaviana es un antecedente histórico de la actio metus de época clásica. Las diferencias existentes entre las dos fórmulas se concretan del siguiente modo: la fórmula Octaviana contendría la expresión «per vim aut(et) metum auferre», mientras que en la fórmula clásica se leería "metus causa gerere (facere)». La eliminación del vocablo vis de la primera fórmula y su evolución histórica que lleva a la segunda se habría ido completando hasta desembocar en la redacción del Edicto Perpetuo de Adriano.

Si nos preguntamos por los motivos posibles de esta desaparición de la vis de la redacción original, hemos de considerar las circunstancias histórico-políticas del momento en que surge y se desarrolla la fórmula Octaviana: se admite que nos hallamos en períodos de fuerte agitación social en el que se hace preciso, tras la dictadura de Sila, el establecimiento de medidas tendentes a obtener la restitución de los bienes que los partidarios del dictador habían conseguido a expensas de personas a quienes amenazaban con denunciarlas; en origen, la acción de la fórmula Octaviana se dirige frente a aquéllos que se habían apoderado de bienes ajenos utilizando la coacción o por amenazas ${ }^{32}$. Estas mismas exigencias histórico-políticas habrían hecho posible el nacimiento de nuevas, y más eficaces, figuras jurídicas en la represión de la violencia contra los intereses particulares, incluyendo la salvaguardia de la estabilidad social y orden público, a lo largo del turbulento siglo I a. C. Si esto es así, la concurrencia con las nuevas instituciones ha debido influir en la evolución de la primitiva acción prevista en la fórmula Octaviana.

Desde esta perspectiva, se ha defendido ${ }^{33}$ que, en la antigua fórmula edictal, los términos vis y metus indicarían, respectivamente, la violencia física y la violencia moral; la restricción del ámbito de aplicación de tal cláusula a los casos de violencia moral, y la supresión de la vis, se habría debido a la posterior inclusión en el edicto del pretor de la cláusula relativa a la llamada actio vi bonorum raptorum, identificada con el edicto de Lucullus del 76 a. C., con la que se sancionarían las conductas calificadas por el ejercicio de la pura violencia física, al menos en su origen histórico.

Desde el punto de vista cronológico, puede afirmarse que la fórmula Octaviana es anterior al 71 a. C.; esto es así gracias al testimonio de Cicerón de in Verr. 2, 3, 65,162 , según el cual, como ya se ha visto, Metelo en dicho año incluye en su edicto el contenido de una ya existente fórmula Octaviana.

Prolongando esta reflexión, se debe también dejar constancia de la duda doctrinal en torno a la identificación del autor de la fórmula que nos ocupa; la incertidumbre se plantea entre dos nombres: Cn. Octavius y L. Octavius, pretores, respectivamente, en el 79 y en el 78 a. C. ${ }^{34}$

${ }^{32}$ Cic. ad Quintum fr. 1, 1, 7, 21; in Verr. 2, 3, 65, 152. Con posterioridad, la restitutio in integrum, ya conocida por Cicerón (pro Flaco 49), habría sido instituída por un pretor urbano generalizando un procedimiento ya usado a título excepcional; la exceptio sería de época de Labeón. Monier, Manuel élémentaire de droit romain 2, París 1954

${ }^{33}$ Maschi, Il diritto romano... cit., p. 642 ss.

${ }^{34}$ Münzer, V. Octaivuis en PWRE 
Con independencia de esta dificultad, parece que puede afirmarse, teniendo en cuenta las circunstancias que rodean al proceso contra Verres, la existencia de una interesante relación entre los procesos criminales, desarrollados de acuerdo con el sistema de la quaestio repetundarum, y los procesos privados basados en la fórmula Octaviana. Y, además, que la citada fórmula se ha de considerar precedente del edicto de $M$.. Lucullus del 76 a. C. ${ }^{35}$, sobre daños y sustracciones violentas, quien no habría incluido la fórmula Octaviana en el edicto correspondiente al período de su mandato.

\section{3.- Edicto de M. Lucullus (actio vi bonorum raptorum).}

Como ya hemos indicado, se debe al pretor peregrino M. Terentius Varro Licinianus Lucullus, en el 76 a. C., una cláusula edictal encaminada a la represión de la violencia ejercida sobre los bienes patrimoniales.

El principal problema sobre la estructura originaria del edicto se plantea en el contraste entre las noticias que nos transmite Cicerón y los comentarios al edicto del jurista Ulpiano:

Iudicium vestrum est, recuperatores quantae pecuniae paret dolo malo familiae $P$. Fabi vi hominibus armatis coactisve damnum datum esse $M$. Tullio. Eius rei taxationem nos fecimus; aestimatio vestra est, iudicium datum est in quadruplum ${ }^{36}$.

Praetor ait: «Si cui dolo malo hominibus coactis damni quid factum esse dicetur sive cuius bona rapta esse dicentur, in eum, qui idfecisse dicetur, iudicium dabo. item si servus fecisse dicetur, in dominum iudicium noxale dabo $»^{37}$.

Mientras Cicerón presenta el nuevo iudicium referido a las hipótesis de dolo malo vi hominibus armatis coactisve damnum datum, el edicto, según Ulpiano, contiene junto al damnum los supuestos de bona rapta y la supresión de la referencia al uso de las armas.

Esta falta de congruencia en los textos ha originado una división de la doctrina romanística en dos grandes corrientes:

$\left.1^{\mathrm{a}}\right)$ La de quienes sostienen que la redacción compilatoria sería el resultado de la fusión, por obra de Justiniano, de dos edictos distintos durante el derecho clásico. Se afirma, en este sentido, la existencia de contradicciones entre los pasajes del comentario de Ulpiano; y, por otro lado, que la noción de daño edictal, en

\footnotetext{
${ }^{35}$ Cic. pro Tullio 8

${ }^{36}$ Cic. pro Tullio 7

${ }^{37}$ D. $47,8,2$, pr. (Ulp. 56 ad ed.)
} 
estrecha relación con la noción de daño aquiliano, no comprende, en origen, los supuestos de sustracción ${ }^{38}$.

$2^{2}$ ) Nos referimos ahora a la posición de los autores que reconocen el origen de la actio vi bonorum raptorum en el edicto de Lucullus y que, desde el primer momento, éste incluye tanto los casos de damnun dare como los de bona rapere: la hipótesis de sustracción, con las mismas agravantes previstas para el daño (dolo malo hominibus armatis coactisve), debió figurar ya en el edicto originario.

Lenel $^{39}$, sostiene que tanto el edicto de Lucullus como el definitivo de Juliano contemplan dos figuras jurídicas: una, el dolo malo hominibus armatis coactisve damnum datum, otra, sobre bona vi rapta. Según este autor, en la redacción clásica no es necesaria la mención de la vis en la primera figura, al estar implícita en el uso de las armas, mientras que es esencial en la segunda; los compiladores, al suprimir el interdicto de vi armata, eliminan todas las demás disposiciones relativas a la vi armata y el término vi de la expresión bona vi rapta que hasta ahora le había dado su carácter distintivo.

Supuesta esta polémica doctrinal, parece oportuno resaltar que el discurso ciceroniano nos da a entender que el edicto, originariamente, va dirigido contra los delitos cometidos por bandas armadas ${ }^{40}$. Desde esta perspectiva y como recientemente se ha defendido ${ }^{41}$, puede mantenerse que la noción de sustracción violenta viene incluída en el concepto edictal de damnum datum y ello por varias razones: a) porque Cicerón en pro Tulio 42 habla de rapinae; b) por la dificultad práctica de distinguir, en los casos de incursión de bandas armadas, entre daños y sustracciones; c) porque parece improbable, y contrario al espíritu de la norma, que el pretor se haya ocupado exclusivamente de sancionar el daño, en tan graves circunstancias, olvidándose de la sustracción violenta, tan frecuente y peligrosa para la seguridad pública; d) la expresión damnum datum, prevista en el edicto de Lucullus, no puede tener el mismo alcance jurídico que el damnum iniuria datum de la lex Aquilia; damnum, en el sentido genérico del edicto, significa toda disminución patrimonial sufrida como consecuencia de una acción antijurídica, incluida la sustracción; las referencias al daño de la lex Aquilia, en cambio, se han de interpretar en sentido estricto como se desprende de los precisos términos legales que lo tipifican.

Es cierto que el delito de furtum tiene orígenes muy antiguos y que incluso la hipótesis de sustracción violenta se ha podido presentar, en un primer momento, como un caso de hurto; sin embargo, el espíritu de la cláusula pretoria nos permite afirmar que el punto de vista edictal no es el de la consideración particular de cada delito sino las graves circunstancias agravantes en que se produce el daño patrimo-

\footnotetext{
${ }^{38}$ Balzarini, Ricerche... cit., p. 58 ss., se ha manifstado, recientemente, partidario de esta doctrina. ${ }^{39}$ Lenel, Das Edictum Perpetuum, Leipzig 1927, p. 391 ss.

${ }^{40}$ Ebert, Die Geschichte des Edikts de hominibus armatis coactisve, Heidelberg 1968, p. 43 ss.

${ }^{41}$ Vacca, Ricerche in tema di actio vi bonorum raptorum, Milano 1972, p. 7
} 
nial antijurídico, con el consiguiente deterioro del orden público que la actuación de bandas armadas puede generar.

De los textos de Cicerón se deduce, en efecto, que el edicto tiene por objeto la represión de una violencia protagonizada por grupos armados, cuya gravedad supera incluso la esfera de lo individual y pone de manifiesto la inestabilidad política de la república:

In hoc iudicium videtis agi de vi, videtis agi de monibus armatis, videtis aedificiorum expugnationes, agri vastationes, hominum trucidationes, incendia, rapinas, sanguine, in iudicium venire... ${ }^{42}$.

Las precedentes consideraciones permiten una interpretación de los términos de la intentio de la fórmula que nos transmite Cicerón (dolo malo familiae hominibus armatis coactisve) y que se concreta del siguiente modo: a) el requisito del dolus malus no se aprecia en el momento del daño sino atendiendo al modo de producirse, es decir, a la constitución de la banda armada (reclutamiento de hombres o depósito de armas con intención de dañar), lo que se considera punible, en símismo considerado, en cuanto produzca cualquier lesión patrimonial ${ }^{43}$; b) la acción de $L u c u l l u s$ reprime la tendencia tanto de familiae de esclavos a organizarse en bandas armadas, con el fin de cometer saqueos y robos, como de los patronos a usarlos, con objeto de hacer valer a la fuerza sus propias razones ${ }^{44}$; c) el uso de la disyuntiva ve en el enunciado hominibus armatis coactisve permite pensar que tanto el uso de armas, aunque sea por parte de uno solo, como la actuación en grupo, aunque no esté armado, tienen cada uno entidad suficiente para constituir el tipo delictivo del que se trata; esto viene confirmado por Cicerón cuando interpreta esta expresión en materia de interdicto de vi armata $^{45}$; la peligrosidad social, que está en la base de este interdicto y también de la cláusula edictal, permite una interpretación de la ratio que inspira estas disposiciones, ya que tal peligrosidad subsiste cuando actúa uno solo armado y cuando actúan varios hombres reunidos.

La precedente interpretación de la fórmula ciceroniana, basada en argumentos de carácter sustancial, más allá de la sola motivación literal o técnica, avala un planteamiento global que, desde una perspectiva de conjunto, estudie las posibles conexiones del originario edicto de Lucullus con las otras medidas que tienen por objeto el castigo de la violencia, especialmente con el interdicto de vi armata e incluso con la lex Plautia.

Según esto, y al menos por lo que se refiere al derecho clásico, encontramos en la jurisprudencia ${ }^{46}$ un ejemplo en el que Ulpiano, citando a Juliano, admite la

\footnotetext{
${ }^{42}$ Cic. pro Tullio 42

${ }^{43}$ Cic. por Tullio 31,32

${ }^{44}$ Cic. pro Tullio 11

${ }^{45}$ Cic. pro Caec. 62,63

${ }^{46}$ D. $43,16,1,32$ (Ulp. 69 ad ed.)
} 
posibilidad de concurso cumulativo entre el interdicto y la acción: el primero para recuperar la posesión del fundo, la segunda para la sanción penal de la sustracción de las cosas muebles allí contenidas en el momento de la deiectio.

Prolongando esta reflexión, se debe considerar, como sucede en los interdictos de vi y de vi armata, que la violencia sancionada con la acción penal no es solamente la de carácter corporal; basta con que se haya producido un daño patrimonial derivado de la alarma social generada por la constitución de bandas o depósito de armas. De este modo, resulta suficiente para hablar de violencia la huída de la víctima cuando ésta venga motivada, incluso, por la intimidación debida a la presencia de un hombre armado. Esta interpretación amplía el concepto de violencia, corporal y moral, común a los interdictos y a la acción penal, posibilitando la represión de cualquier actividad contraria a la tranquilidad ciudadana.

En definitiva, la vis, en el sentido jurídico que la tratamos, alude a los atentados contra la integridad patrimonial de la persona (los que atacan la integridad física o la vida se enfocarían como delito de iniuria o como represión criminal del parricidium) y comprende tanto la acción material directa, que perturba o impide el ejercicio de las facultades posesorias sobre los bienes, como la amenaza e intimidación contrarias a este mismo ejercicio. Los remedios jurídicos expuestos son de la iniciativa privada y en las acciones penales no se reducen a la indemnización pues alcanzan carácter sancionador.

\section{4.- Vis en la legislación}

Las consideraciones anteriores, sobre los principios de la normativa edictal represiva de la vis, muestran cómo junto al problema de la reparación del daño, a favor de la víctima a título particular, aparece el de la violencia organizada, traducido en la consiguiente alteración del orden público, en última instancia y conectado con la grave inestabilidad política y social que vive la república s. I. a. C. Ante tal situación, el Derecho ha de buscar la armonización y convergencia de las medidas ya expuestas con otras nuevas introducidas mediante disposiciones legislativas.

Este planteamiento permite distinguir la violencia frente a los particulares, constitutiva del correspondiente delito, de la violencia entendida como agitación, rebelión o revolución ciudadana que denominamos crimen vis.

Presentada así la cuestión, cabe preguntarse si la legislación sobre violencia, además de crear derecho criminal, puede contener normas sobre violencia privada y, por otro lado, si determinados episodios de violencia pueden ser simultáneamente perseguidos como crimen y como delito.

Una respuesta afirmativa de estas cuestiones supone: que hechos ya contemplados en los interdictos posesorios y en las acciones penales pretorias presentan otra dimensión en el derecho público; el concurso cumulativo de procedimiento privado

y del iudicium publicum: el primero se orienta a remediar materialmente una pérdida 
patrimonial, el segundo a castigar todo intento de alterar por la fuerza el orden establecido; en consecuencia, como crimen vis se castigan casos de vis privada que también alteran la convivencia ciudadana, y casos de la más grave vis pública que suponen un ataque frontal al régimen político; esta distinción se ha de traducir en las formas de procedimiento o en el carácter de la pena.

Veamos ahora en qué medida podemos admitir una respuesta afirmativa a las preguntas planteadas. Que la legislación de vi puede contener normas, también, sobre violencia privada se desprende de las Instituciones de Gayo y de Justiniano, cuando unen las leyes Iulia et Plautia de vi:

Inhibet usucapionem vi possessarum (rerum) les Iulia et Plautia ${ }^{47}$.

Igualmente, el jurista Juliano trata de modo conjunto ambas leyes:

Quia lex Plautia et Iulia ea demum vetuit longa possessione capi, quae vi possessa fuissent, non etiam ex quibus vi quis deiectus fuisset $t^{48}$.

En segundo lugar, el principio de coexistencia y de confluencia entre iudicium publicum y procedimientos privados podemos considerarlo consolidado en el derecho clásico. En el amplio apartado de los ilícitos perseguibles con medios de represión públicos y privados, nos vamos a referir solamente a dos: la expulsión violenta de la posesión de bienes inmuebles y la sustracción violenta de bienes muebles.

Sobre el asunto de la posesión, los comentarios al edicto de Paulo plantean la relación entre interdictum unde vi y accusatio vis lege Iulia:

Interdum evenit ut praeiudicum (per privatum iudicium) iudicio publico fiat, sicut in actione legis aquiliae et furti et vi bonorum raptorum et interdicto unde vi et de tabulis testamenti exhibendis ${ }^{49}$.

Este fragmento comprende varios casos en los que el hecho ilícito es sancionado en virtud de los mecanismos de derecho privado y a través de la represión pública; y se presenta como argumento para demostrar que el orden de utilización de dichos medios es libre en determinados supuestos ${ }^{50}$.

Esta hipótesis se encuentra comprendida, igualmente, en el Código Teodosiano; cuando se refiere al interdicto unde vi en caso de expulsión violenta añade:

${ }^{47}$ G. 2,45 ; I. 2, 6, de usucapionibus

${ }^{48}$ Lib. 44 dig., D. 41, 3 de usurpationibus et usucapionibus 33, 2. Este texto y los dos anteriores prohiben la usucapión de una cosa que ha sido desposeída violentamente; lo que lleva a pensar que las leyes represoras de la violencia pública pueden contemplar determinados aspectos de la violencia privada.

${ }^{49}$ D. 48,1 , 4, Paulo 37 ad edictum

${ }^{50}$ Avonzo, Coesistenza e conessione tra iudicium publicum e iudicium privatum, BIDR 1956, p. 154 
non prohibetur tamen etiam lege Iulia de vi publico iudicio instituere accusationem $^{51}$.

A la misma situación se refiere C. I. 8, 4, 4, donde se afirma que tanto la defensa interdictal como la represión criminal se otorgan al ofendido frente a quien con violencia lo haya desposeído.

Otros textos del Digesto y del Código Justiniano avalan la idea de la coexistencia $^{52}$; en definitiva, se puede y se debe afirmar que los dos medios procesales tienen fines jurídicos diversos y por ello habría sido absurdo impedir su acumulación ${ }^{53}$.

Expuestas estas ideas, y atendiendo a la hipótesis del daño y sustracción violentos, se ha sostenido que la concurrencia es principio clásico, probablemente ya previsto en la lex Iulia de $v t^{i 4}$. En efecto, la represión criminal de la rapina viene afirmada en un pasaje que podemos considerar genuino en lo sustancial:

In eadem causa sunt, qui pessimo exemplo convocatu seditione villas expugnaverint et cum telis et armis bona rapuerint. Item tenetur, qui ex incendio rapuerit aliquid praeter materiam ${ }^{55}$.

Idéntica afirmación podemos hacer respecto al daño producido por hombres armados o en grupo sin armas, sancionado con la acción pretoria creada por Lucullus:

In eum, cuius dolomalo hominibus coactis (armatisve) ${ }^{56}$ damni quid datum esse dicatur, non debet cogi actor omissa actione civili crimen intendere ${ }^{57}$.

Considerando válida esta reflexión para el derecho clásico, la duda surge, sin embargo, en el momento de afrontar el origen de este principio de concentración de medios procesales. Sobre este punto, y antes de ocuparnos de las leyes sobre la violencia, es posible avanzar una hipótesis favorable a su inicio ya a finales de la república. Esta se basa en una argumentación de carácter histórico: la legislación y las acciones penales edictales aparecen en plena crisis de las instituciones republicanas; el edicto de Lucullus precisamente constituye una medida indirecta de garantía del orden público (medida directa sería la lex Plautia de vi) y presenta un

${ }^{51}$ C. Th. $9,20,1,1$

${ }^{52}$ Como son D. $48,6,5,1$ y C. I. $7,62,1$

${ }^{53}$ Avonzo, Coesistenza... cit., p. 160

${ }^{54}$ Lauria, Accusatio-Inquisitio, Atti Accad. Sc. Mor. Pol. di Napoli 56, 1933, reafirma la doctrina tradicional, según la cual la rapina es originariamente contemplada en la lex lulia: opinión puesta en duda por Niedermeyer, Crimen plagii und crimen violentiae, Studi Bonfante II. Avonzo, Coesistenza ... cit., p. 150 ss., considera que el problema de las relaciones entre la acción pretoria y el iudicium publicum ex lege Iulia de vi habría tenido lugar en el siglo II.

${ }^{55}$ D. 48, 6, 3, 2-3 (Marciano 14 inst.), referido a la ley Julia de violencia privada según Lenel, Palingenesia, MARC. n. 164.

${ }^{56}$ Lenel, Palingenesia, ULP. n. 1311

${ }^{57}$ D. $48,2,15$ (Ulp. 56 ad edictum). Véase también D. 47, 8, 2, 1 
específico contenido político-social que responde plenamente a las exigencias de su tiempo ${ }^{58}$. El testimonio de Cicerón es inequívoco en este sentido:

cumque ea consuetudo non solum ad res privatorum sed ad summam rem publicam pertinere videretur, $M$. Lucullus, qui summa aequitate et sapientia ius dixit, primus hoc iudicium composuit... ${ }^{59}$.

En suma, los supuestos de violencia que se han tratado hasta ahora no sólo afectan a los particulares, también lo hacen al mismo dominio de la república. Ahora bien la extensión del crimen vis así como la distinción entre los supuestos de mayor o menor gravedad y su correspondiente sanción han de ser fijados por las leyes.

La primera ley de la que tenemos noticia es la lex Plautia de vi. Sobre la determinación de la fecha de su aparición y sobre su identificación o no con la llamada lex Lutatia, no reina el acuerdo en la doctrina. Esto supuesto, distinguimos dos grandes corrientes:

$\left.1^{\text {a }}\right)$ la de quienes hablan únicamente de la lex Plautia

$2^{a}$ ) la de quienes sostienen la existencia de una lex Plautia y de una lex Lutatia de vi.

En el primer apartado situamos la obra de $\mathrm{Mommsen}^{60}$, quien se adhiere a una teoría ya enunciada en siglo XVII ${ }^{61}$, según la cual la lex Plautia de vi sería una lex Plautia de reditu Lepidanorum, citada por Cicerón y Aulo Gelio ${ }^{62}$, probable plebiscito de un tribuno Plautius, que otorgaría la amnistía a los partidarios de Lépido refugiados en España y que al mismo tiempo, dispondría penas para el futuro; habría sido promulgada en el 77 a. C. cuando $Q$. Lutatius Catulus acaba de poner fin a una guerra civil que amenzaba con la desintergación de la república. Por este motivo, la lexPlautia se identifica con la Lutatia ya que siendo Lutacio procóncul, y no pudiendo efectuar la rogatio, habría inducido al tribuno Plautio a presentarla al pueblo.

Estas identificaciones y la cronología han sido, justamente, puestas en duda por la doctrina ${ }^{63}$. En efecto, el año $78 \mathrm{M}$. Emilio Lépido alcanza el consulado con Q. Lutacio Catulo; las fricciones pronto surgen entre ellos: Catulo es un convencido aristócrata del partido de Sila, mientras que el programa de Lépido recoge las principales reivindicaciones de los grupos excluídos del sistema ${ }^{64}$. Cuando los ecos de la agitación de Lépido llegan a Etruria: en una de sus comunidades, Fiessolae, los campesinos desposeídos expulsan a sus colonos silanos, recuperan sus propiedades e inician una revuelta que llega a adquirir caracteres de sedición. Por otro lado, el

\footnotetext{
${ }^{58}$ Balzarini, Ricerche... cit., p. 58 ss.

${ }^{59} \mathrm{Cic}$. pro Tullio 8

${ }^{60}$ Mommsen, Derecho Penal Romano, 1899, trad. de P. Dorado, Bogotá 1976, p. 410 ss.

${ }^{61}$ Sobre el tema, se cita ya bibliografía de los siglos XVII y XVII: Sigonius, DeiudiciuII,33 (Thesaurus antiquitatum Romanorum de Gravius II, 1694, p. 1794); Gravina, Originum iuris civilis libri III, 2, 1757 , p. 435

${ }^{62}$ Cic. de lege agraria 2, 4, 10; Aulo Gelio 13, 3, 5

${ }^{63}$ Cousin, Introducción al pro Caelio, Colección Les Belles Lettres, París 1969

${ }^{64}$ Roldán, La República romana, Madrid 1991, p. 510
} 
cónsul rebelde se rodea de descontentos y de enemigos del régimen, como el hijo de Cinna. Y es a comienzos del 77, encontrándose Roma sin magistrados ordinarios al no haberse celebrado elecciones, cuando el interrex Apio Claudio recurre al senatusconsultum ultimum, mediante el cual se solicita de todo detentador del imperium acudir en defensa del estado; de este modo, Pompeyo, como propretor, combina sus fuerzas con Catulo, ahora procónsul. La derrota de Lépido, sin embargo, no impide que el grueso de sus fuerzas tomen el camino de Hispania para incorporarse al ejército de Sertorio.

No parece que en estas circunstancias se haya producido la amnistía; ésta, según se desprende de Suetonio, es posterior y relacionada con L. Cinna, cuñado de César, quien habría asegurado su regreso de España:

L. etiam Cinnae uxoris fratri et qui cum eo civili discordia Lepidum secuti,postnecem consulis ad Sertorium confugerant, reditum in civitatem rogatione Plotia confecit habuitque et ipse super ea re contionem ${ }^{65}$.

Y si nos fijamos en los Fasti, la actuación del tribuno Plautius (o Plotius) habría tenido lugar alrededor del año $73^{66}$.

Presentando ahora el problema desde la perspectiva de quienes mantienen la existencia de dos leyes, Ferrini ${ }^{67}$ sigue la opinión que se fundamenta en la lex Plautia como la más antigua sobre el crimen vis: plebiscito debido al tribuno $M$. Plautius Silvanus y votado en el 89 a. C., época de la llamada guerra social. De este mismo año y de idéntico autor son la lex Plautia iudiciaria, la lex Plautia agraria y la lex Plautia Papiria de civitate sociis danda ${ }^{68}$. Entre las consecuencias políticas de la guerra figuran las derivadas de la inclusión de los itálicos en el cuerpo ciudadano y el reforzamiento del Senado con la creación de un nuevo sistema de selección de jurados que reduce a la mínima expresión la presencia de los caballeros.

Junto a esto, la lex Plautia sancionaría ciertos actos de violencia sobre los patrimonios particulares, prohibiendo la usucapión de la cosa poseída violentamente.

Transcurridos unos años, una vez sofocada la sublevación lepidiana, con objeto de borrar sus dolorosos efectos, se publica una nueva ley sobre procedimiento penal público (también tiene lugar la publicación del edicto del pretor Lúculo). La importancia práctica de la nueva tipificación de la vis crimial residiría más que en los hechos, que entraban también, en general, en el horizonte de la lesa magestad, en la rapidez del procedimiento. La lex Lutatia habría llegado a permitir ut etiam diebus festis ludisque publicis de vi quaeri posset. Cicerón, en el comienzo de su

\footnotetext{
${ }^{65}$ Suet. Iul. 5

${ }^{66}$ Niccolini, Fasti tribunorum plebis ab an. $260 / 494$ usque ad an. 731/23, Pissa 1898, p.. 37-71, establece el año $681 / 73$

${ }^{67}$ Ferrini, Diritto penale romano, Milano 1889 , p. 230 ss.; parte de la antigua doctrina fija esta ley en 89 a. C.: Rein; Das Criminall Recht der Römer, Leipzig Köhler, 1844

${ }^{68} \mathrm{Cuq}$, Véanse las voces correspondientes en D. S.
} 
discurso en defensa de M. Celio (56 a. C., cuando frente a las bandas armadas de Clodio, surgen los sicarios de Milón al servicio de los optimates), se pregunta ante los jueces cuál puede ser la terrible gravedad de esta causa que continúa en días festivos cuando se han suspendido todas las actividades del foro; $y$ afirma que esto sólo sería posible, cuando corre riesgo el propio estado, en virtud de una ley que manda instruir proceso a los ciudadamos sediciosos y criminales que, a mano armada, hayan asediado al Senado, hayan ultrajado a los magistrados o asaltado a la república.

Caelius es acusado, en efecto, de vi conforme a una ley de la que $Q$. Lutatius Catulus sería el autor:

De vi quaeritis. Quae lex ad imperium, ad maiestatem, ad statum patriae, ad salutem omnium pertinet, quam legem $Q$. Catulus armata dissensione civium rei publicae paene extremis temporibus tulit, quaque lex sedata illa flamma consulatus mei fumantis reliquias coniurationis extinsit ${ }^{69}$.

El autor de la ley es Q. Lutatius Catulus, colega de M. Emilio Lépido, y habría sido adoptada durante su proconsulado en el 77 , a continuación de un senadoconsulto último en circunstancias excepcionales.

Aceptada como más probable esta teoría, cabe ahora preguntarse qué relación guarda con la anterior lex Plautia. Aquí, la doctrina vuelve a dividirse: mientras un sector estima que la lex Lutatia supone sólo un cambio del procedimiento de la lex Plautia, limitado a una declaración de extrema urgencia, o que establece una quaestio extraordinaria (como será la lex Pompeia del 52) para casos de extrema gravedad $^{70}$, la doctrina dominante y más antigua entiende que cada ley contempla su propio supuesto ilícito: la ley Plautia, la vis privata y la ley Lutacia, la vis publica ${ }^{71}$. En este sentido, entendemos la vis privata como todo acto antijurídico de violencia, moral o física, armada o no, tal y como la consideran los interdictos y las acciones penales edictales, que no sólo produce un perjuicio en el patrimonio de los particulares sino que además pone en peligro la estabilidad social y el orden público. Estoúltimo, entendido en el conocido sentido ciceroniano non solumadres privatorum sed ad summam rem publicam pertinere videtur (pro Tullio 8), justifica tanto la existencia de acciones penales pretorias como la concurrencia con mecanismos de represión criminal pública (ley Plautia).

Entendemos la vis publica, en el sentido que se desprende del discurso ciceroniano en defensa de M. Celio, como aquella actividad violenta dirigida directamente contra las instituciones políticas, con riesgo del propio estado, y que por su extrema gravedad se ha de reprimir con arreglo a un procedimiento de urgencia (ley Lutacia).

\footnotetext{
${ }^{69}$ Cic. pro Cael. 70

${ }^{70}$ Weinmayr, Ueber lex Plautia de vi und lex Lutatia, Progr. Ausburg 1888, p. 15-28

${ }^{71}$ En esta dirección, se cita ya bibliografía del siglo XVII:Delegibus romanis. Thesaurus antiquitatum Romanorum de Graevius II, Traiecti ad Rh. 1649, p. 1102
} 
En efecto, el núcleo central de la acusación contra Celio se basa en los siguientes supuestos:
a) haber golpeado un senador durante los comicios ${ }^{72}$;
b) haber participado en una seditio en Nápoles ${ }^{73}$;
c) haber violado la inmunidad de algunos legados alejandrinos ${ }^{74}$.

Y refiriéndonos a la lex Plautia, la hipótesis que mantenemos es la que mejor explica el alcance de los fragmentos en que aparece tratada:

a) cuando se prohibe la usucapión de las cosas cuya posesión se ha alcanzado violentamente ${ }^{75}$;

b) cuando se aplica en relación con la conjuración de Catilina, Salustio nos informa que éste había sido acusado ex lege Plautia:

Catilina... lege Plautia interrogatus erat ab L. Paulo ${ }^{76}$.

No sabemos exactamente por qué hechos concretos ${ }^{77}$ aunque se tiende a pensar que sería por organizar bandas armadas, saqueos, stragos y similares ${ }^{78}$.

La ley Plautia también permitió juzgar a ciertos personajes implicados en la conjuración ${ }^{79}$; entre ellos a $P$. Sulla acusado de reclutar una banda de gladiadores y fomentar desórdenes ${ }^{80}$

c) cuando sirve de base a la acusación contra M. Saufeius, compañero de Milón, por haber tomado posiciones en determinados lugares con hombres armados:

quod loca edita occupasset et cum telo fuisset; nam dux fuerat operarum Milonis $^{81}$

d) incluso Clodius fue acusado por Milón de vi ex lege Plotia ${ }^{82}$, posiblemente, por constitución de bandas armadas, incendios, devastaciones y otros análogos

e) otra acusación ex lege Plautia es la intentada frente a $M$. Tuccius por $C$. Sempronius Rufus, recordada en carta de Celio a Cicerón, pero sin indicar los hechos en que se basa ${ }^{83}$.

Las fuentes mencionan nuevas acusaciones $d e v i$, aunque sin especificar la ley constitutiva de la quaestio, comola formulada contra P. Sestius, compañero de Milón ${ }^{84}$, en el 56 por haber reclutado hombres durante su tribunado del año precedente.

\footnotetext{
${ }^{72}$ Cic. pro Cael. 19

${ }^{73}$ Cic. pro Cael. 23

${ }^{74}$ Cic. pro Cael. 23

${ }^{75}$ G. 2 , 45; I. 2, 6;; D. 41, 3, 33, 2

${ }^{76}$ Salustio, Catil. 31, 4

${ }^{78}$ Salustio, Catil. 27,2

${ }^{79}$ Invectiva sallusti in Ciceronem 2,3

${ }^{80} \mathrm{Cic}$. pro Sulla 54,56

${ }^{81}$ Ascon. in Mil. p. 55 (ed. Clark)

${ }^{82}$ Cic. pro Mil. 13, 55

${ }^{83}$ Cic. ad fam. $8,8,1$

${ }^{84}$ Cic. pro Sest. 75,80
}

${ }^{77}$ Sí conocemos que Cicerón descubrió el complot ante el Senado; que los principales conjurados fueron encarcelados, excepto Catilina; que inmediatamente después se decidió en el Senado la pena de muerte para los encarcelados, a pesar del brillante intento oratorio de César por salvar sus vidas; y que Catilina, al conocer la suerte de sus compañeros, decidió la rebelión abierta en la que perdió la vida. 
Posteriormente, una lex Pompeia de vi del 52 a. C., que no reformaría lo instituido por la lex Plautia, creó una quaestio extraordinaria de caede quae in Appia via facta esset, in qua P. Clodius occisus esset ${ }^{85}$. Ley propuesta por el cónsul Cn.Pompeius para castigar ciertos actos de violencia que ya habían tenido lugar en los alrededores de Roma y en la ciudad: de vi, quae nominatim caedem in Appia via factum et incendium curiae et domum $M$. Lepidi interregis oppugnatam comprehendit ${ }^{86}$. Conforme a tal ley, fueron procesados Milón y algunos de sus compañeros $^{87}$ : según parece, M. Saufeius, tras ser absuelto exlege Pompeia, fue nuevamente acusado ex lege Plautia. La ley habría agravado la pena y aligerado el procedimiento:

poena graviore et forma iudiciorum breviore ${ }^{88}$;

y contendría reglas sobre el número y sorteo de los jueces, sobre el derecho de recusación de las partes, sobre audición de testigos y sobre la actuación de los defensores:

Lex Pompeia... iubebat ut prisuquam causa ageretur testes per triduum audirentur, dicta eorum iudices confirmarent, guarta die adesse omnes in diem posterum iuberentur ac coram accusatore ac reo pilae in quibus nomina iudicium fieret unius et LXXX; qui numerus cum sorte contigisset ei protinus sessum irent; tum ad dicendum accusator duas horas, reus tres haberet, resque eodem die illo iudicaretur; prius autem quam sententiae ferretur quinos ex singulis ordinibus accusator totidem reus reiiceret, ita ut numero iudicum relinquerentur qui sententiae ferrent quinquaginta et unus $^{89}$.Procedimiento especial que limita el número de abogados, suprime los laudatores y concede dos horas a la acusación, tres a la defensa; y concreta la audición de testigos en los cuatro días que preceden al proceso.

Si estas son características de un procedimiento extraordinario de vi, se trata ahora de los caracteres del modo de proceder en los demás.

En este apartado, las fuentes permiten afirmar que el conocimiento de las causas de la violencia no es encomendado a ningún alto tribunal especial; tales causas siguen formando parte de la competencia del pretor urbano $0^{90}$. El presidente, quaesitor, es elegido de entre los jurados por el pretor urbano; para su elección pudo emplearse el sorteo aunque ésta no sería regla general; ejerce sus funciones en el caso determinado y recibe del pretor urbano el proceso instruído y el jurado constituído ${ }^{91}$.

${ }^{85}$ Cic. pro Mil. 6,15

${ }^{86}$ Ascon. in Mil.p. 31 (Kiessling-Schoell)

${ }^{87}$ Ascon. in Mil. p. 48 ss. (Kiessling-Schoell)

${ }^{88}$ Ascon. in Mil. p. 31 (Kiessling-Schoell)

${ }^{89}$ Ascon. in Mil. p. 34 (Kiessling-Schoell)

${ }^{90}$ Mommsen, D. penal romano cit., p. 416. Lecrivail, V.Vis privata et publica y Humbert (Lcerivain) V. Iudicia publica en D. S. 24,50

${ }_{91}^{1}$ Dio. Cass. 59, 7; Cic. ad Quint. 2, 1, 2; pro Sest. 89, 95; ad fam. 1, 9, 15; 5, 3, 2; de harusp. resp. 
A esto se añade la necesidad de la acusación privada, lo que ha permitido manifestar que estas quaestiones, en el fondo, constituyen un procedimiento civil reforzado, pues el magistrado centra su labor fundamentalmente en un iudicium exercere $^{92}$.

Especial atención merecen las leges iudiciariae, organizadoras de la composición de los jurados, de una importancia política de primer orden y cuya historia se halla íntimamente unida a la de la constitución romana y a las luchas entre senadores y caballeros: si la ley Cornelia iudiciaria de Sila ( 81 a. C.) entrega los tribunales al Senado, la reacción se produce en el 70 con la ley Aurelia, que se mantiene básicamente hasta la dictadura de César, cuya lista de 360 nombres, sobre la que se obtienen 81 por sorteo, permite en el 52 el proceso de Milón y sus partidarios ${ }^{93}$.

En un último punto, y a propósito de la pena prevista en las causas de violencia se ha entendido que corresponde la aquae et ignis interdictio ${ }^{94}$. Esta interdicción del agua y del fuego, bajo la amenaza de pena capital en caso de quebrantamiento, se comenzaría a aplicar a los ciudadanos alrededor de la época de Sila en los crímenes contra el estado y en el de homicidio. Otros ilícitos como la vis y el ambitus recibirían el mismo tratamiento ${ }^{95}$.

Sin embargo, esta posición no es unánime: probablemente con mejor criterio, se piensa que la pena prevista en la ley Plautia tendría carácter pecuniario ${ }^{96}$. Si admitimos la existencia de una ley de vi de la época de César ${ }^{97}$, que sería una reproducción de leyes anteriores pero con una sanción más severa (Suet. in Iulio, 42: Poenas facinorum auxit...), y que la pena en época de César es la aquae et ignis interdictio, puede concluirse que ésta no es la sanción originaria ${ }^{98}$.

${ }^{92}$ Humbert (Lecrivain), V. Iudicia publica en D. S.

${ }^{93}$ Lecrivain, V. Iudiciariae leges en D. S.

${ }^{94}$ Cic. Phil. 1, 9, 23; pro Sull. 31, 32; pro Sest. 146.

${ }^{95}$ Mommsen, D. Penal . . cit., p. 599

${ }^{96}$ Laboulaye, Essai sur les lois criminelles des romains, París 1845, p. 293 n. 2, se remite aquí a la autoridad de Waechter, Neues Archiv. des Criminal Rechtes, v. XIII p. 8 ss.

${ }^{97}$ Cic. Phil. 1, 21

${ }^{98}$ Laboulaye, Essai..., cit., p. 308 